Note

\section{Isolation of Harman and Norharman from Nocardia sp. and Their Inhibitory Activity against Plant Seedlings}

\author{
Ken Yomosa, ${ }^{\dagger}$ Akira Hirota, \\ Heiichi SAKAI ${ }^{\dagger \dagger}$ and Akira IsOGaI* \\ Department of Agricultural Chemistry, \\ University of Osaka Prefecture, \\ Sakai, Osaka 591, Japan \\ *Department of Agricultural Chemistry, \\ The University of Tokyo, \\ Bunkyo-ku, Tokyo 113, Japan \\ Received June 27, 1986
}

Numerous studies on the metabolites from Streptomycetaceae have been reported, while reports about metabolites from Actinomycetes, except for Streptomycetaceae, are comparatively few. Generally speaking, Actinomycetes isolated from soil samples are mostly Streptomycetaceae and, in addition, Actinomycetaceae and Actinoplanaceae grow slowly.

In the course of screening for new bio-active metabolites produced by rare Actinomycetes, the strain P-9 was noticed to produce several substances, positive to Dragendorff's reagent, which had inhibitory activity against lettuce seedlings. The P-9 strain was isolated from a soil sample and determined to belong to Nocardia sp. judging from its cell wall type and morphological features. This strain was cultivated for $96 \mathrm{hr}$ at $30^{\circ} \mathrm{C}$ by a jar-fermentor in the following medium: glucose, $15 \mathrm{~g}$; yeast extract, $2 \mathrm{~g}$; polypepton, $2 \mathrm{~g}$; meat extract, $1 \mathrm{~g}$; and adecanol, $0.1 \mathrm{~g}$, in $1,000 \mathrm{ml}$ of distilled water.

The culture filtrate was adjusted to $\mathrm{pH} 9$ with $2 \mathrm{~N} \mathrm{NaOH}$ and extracted with ethyl acetate. The organic layer was then extracted with $0.1 \mathrm{~N} \mathrm{HCl}$ solution. This layer was adjusted to $\mathrm{pH} 10$ with aqueous ammonia and extracted with ethyl acetate. The organic layer was then concentrated in vacuo and was twice subjected to silica gel column chromatography (a benzene-acetone) solvent system). The substances (9-B and 9-C) positive to Dragendorff's reagent were eluted with benzene-acetone $(80: 20)$, and this eluate was subjected to silica gel column chromatography (chloroform saturated with aqueous ammonia). The fraction containing the 9-B substance (I) was first eluted and was subjected to Sephadex LH-20 column chromatography (methanol). I was crystallized from cold acetone as a yellow powder, $\mathrm{mp} 230 \sim 232^{\circ} \mathrm{C}$ (decomposition), and had UV absorption maxima (in methanol) at 234,286 and $346 \mathrm{~nm}$. The fraction containing the 9-C substance (II) was also subjected to Sephadex LH-20 column chromatography (methanol). II was obtained as a white powder by crystallization from cold acetone, $\mathrm{mp}$ $196 \sim 198^{\circ} \mathrm{C}$ (decomposition), and had UV absorption maxima (in methanol) at 232, 286 and $347 \mathrm{~nm}$. The yield of I and II from a 200 liter broth was 20 and $15 \mathrm{mg}$, respectively.

By high resolution mass spectrometry, the molecular formula of I was determined to be $\mathrm{C}_{12} \mathrm{H}_{10} \mathrm{~N}_{2}\left(\mathrm{M}^{+}\right.$ $m / z$ 182.0877; calcd. 182.0845). The $400 \mathrm{MHz}{ }^{1} \mathrm{H}-\mathrm{NMR}$ spectrum of $\mathbf{I}$ (in $\left.\left(\mathrm{CD}_{3}\right)_{2} \mathrm{CO}\right)$ indicated that $\mathbf{I}$ was harman (1-methyl- $\beta$-carboline, Fig. 1): $\delta 2.78\left(3 \mathrm{H}, \mathrm{s}, 1^{\prime}-\mathrm{H}_{3}\right), 7.25$ $(1 \mathrm{H}, \mathrm{ddd}, J=8.0,7.0$ and $1.0 \mathrm{~Hz}, 6-\mathrm{H}), 7.52(1 \mathrm{H}$, ddd, $J=8.2,7.0$ and $1.0 \mathrm{~Hz}, 7-\mathrm{H}), 7.60(1 \mathrm{H}, \mathrm{br}$. dd, $J=8.2$ and $1.0 \mathrm{~Hz}, 8-\mathrm{H}), 7.89(1 \mathrm{H}$, br. d, $J=5.5 \mathrm{~Hz}, 4-\mathrm{H}), 8.19(1 \mathrm{H}$, br. dd, $J=8.0$ and $1.0 \mathrm{~Hz}, 5-\mathrm{H}), 8.26(1 \mathrm{H}, \mathrm{d}, J=5.5 \mathrm{~Hz}, 3-$ $\mathrm{H})$ and $10.62(1 \mathrm{H}$, br. s, $9-\mathrm{H})$. Furthermore, the ${ }^{13} \mathrm{C}-\mathrm{NMR}$ spectrum of $\mathbf{I}$ (in $\left(\mathrm{CD}_{3}\right)_{2} \mathrm{CO}$ ) supported this identification: ${ }^{1)} \delta 21.1\left(\mathrm{C}-1^{\prime}\right), 113.2(\mathrm{C}-4), 113.7$ (C-8), 120.8 (C-7), 122.8 (C-5), 123.1 (C-11), 127.4 (C-12), 129.1 (C-6), 136.2 (C-10), 139.5 (C-3), 142.1 (C-13) and 143.6 (C-1). The high resolution mass spectrum of II determined the molecular formula of II to be $\mathrm{C}_{11} \mathrm{H}_{8} \mathrm{~N}_{2}\left(\mathrm{M}^{+} \mathrm{m} / \mathrm{z}\right.$ 168.0736; calcd. 168.0688). II was identified as norharman ( $\beta$-carboline, Fig. 1) by the $400 \mathrm{MHz}{ }^{1} \mathrm{H}-\mathrm{NMR}$ spectrum (in $\left.\left(\mathrm{CD}_{3}\right)_{2} \mathrm{CO}\right): \delta 7.21(1 \mathrm{H}$, ddd, $J=8.0,7.0$ and $1.0 \mathrm{~Hz}, 6-\mathrm{H})$, $7.50(1 \mathrm{H}, \mathrm{ddd}, J=7.5,7.5$ and $1.0 \mathrm{~Hz}, 7-\mathrm{H}), 7.60(1 \mathrm{H}, \mathrm{dd}$, $J=8.2$ and $1.0 \mathrm{~Hz}, 8-\mathrm{H}), 8.00(1 \mathrm{H}$, br. $\mathrm{d}, J=5.5 \mathrm{~Hz}, 4-\mathrm{H})$, $8.28(1 \mathrm{H}$, br. d, $J=8.0 \mathrm{~Hz}, 5-\mathrm{H}), 8.33(1 \mathrm{H}, \mathrm{d}, J=5.5 \mathrm{~Hz}$, 3-H), $8.90(1 \mathrm{H}$, br.s, $1-\mathrm{H})$ and $10.63(1 \mathrm{H}$, br. s, $9-\mathrm{H}) .{ }^{2}$

Harman (I) has already been isolated from plants, ${ }^{3)}$ sake, ${ }^{4)}$ mushroom, ${ }^{5}{ }^{5}$ Streptomyces ${ }^{6)}$ and marine dinoflagellate. ${ }^{7}$ It is known that I has monoamine oxidase-inhibiting activity $^{8)}$ and cAMP phosphodiesterase-inhibiting activity. ${ }^{9)}$ Norharman (II) has also been isolated from Streptomyces $\left.{ }^{6}\right)$ and marine dinoflagellate ${ }^{7)}$ and it inhibits monoamine oxidase ${ }^{8)}$ However, the biological activity of $\mathbf{I}$ and II against plants has not previously been reported and,

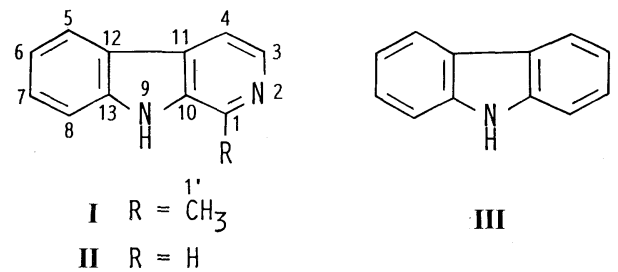

FIG. 1. Structures of Harman (I), Norharman (II) and Carbazole (III).

\footnotetext{
† Present address: Kirin Brewery Co., Ltd., Takasaki 370-12, Japan.

$\dagger$ Present address: Tamagawa University, Machida 194, Japan.
} 
therefore, the biological activity of I and II against rice and lettuce seedlings was tested. I reduced the root elongation of rice seedlings (Oryza sativa L., cv. Nihonbare) by $10 \%$ at $100 \mathrm{ppm}$, and II reduced it by $20 \%$ at $100 \mathrm{ppm}$. I also reduced the root elongation of lettuce seedlings (Lactuca sativa cv. Great Lakes 366) by $50 \%$ at $40 \mathrm{ppm}$, and II reduced it by $50 \%$ at $20 \mathrm{ppm}$. Interestingly, carbazole (III), an analogue of norharman, promoted the root elongation of lettuce seedlings by $30 \%$ at $50 \mathrm{ppm}$. Accordingly, the tertiary amine group which reacts with Dragendorff's reagent seems to have played an important role in the inhibitory activity of $\mathbf{I}$ and II in the lettuce seedlings assay.

As already noted, the metabolites from Actinomycetes, except for Streptomycetaceae, have not been studied much. Although Nocardia sp. has been studied for many years, small numbers of antibiotics from Nocardia sp. have been discovered ${ }^{10)}$ and biologically active substances from Nocardia sp., except for antibiotics, have been less reported.

Consequently it is significant that biologically active substances, harman and norharman, were isolated from a strain of Nocardia sp.

Acknowledgments. We wish to express our thanks to Dr. H. Hirota of the Department of Chemistry, The University of Tokyo, for his measurement of high resolution mass spectra, and to Mr. K. Furihata of the Institute of Applied Microbiology, The University of Tokyo, for his measurement of $400 \mathrm{MHz}{ }^{1} \mathrm{H}-\mathrm{NMR}$ spectra. We are also grateful to Dr. J. Ueda of the College of
Integrated Arts and Sciences, University of Osaka Prefecture, for the generous supply of rice seed, and to $\mathrm{Mr}$. T. Kudo of the Japan Collection of Microorganisms, The Institute of Physical and Chemical Research, for his helpful discussion on the taxonomical study.

\section{REFERENCES}

1) T. Ohmoto and K. Koike, Abstracts of Papers, The 103rd Annual Meeting of the Pharmaceutical Society of Japan, Tokyo, April 1983.

2) F. Balkau and M. L. Heffernam, Aust. J. Chem., 26, 1501 (1973).

3) W. H. Perkin and R. Robinson, J. Chem. Soc., 115, 967 (1919); T. Ohmoto and K. Koike, Chem. Pharm. Bull., 30, 1204 (1982).

4) S. Takase and H. Murakami, Agric. Biol. Chem., 30, 869 (1966).

5) T. Takeuchi, K. Ogawa, H. Iinuma, H. Suda, K. Ukita, T. Nagatsu, M. Kato, H. Umezawa and O. Tanabe, J. Antibiot., 26, 162 (1973).

6) T. Arai, K. Yazawa, Y. Mikami, A. Kubo and K. Takahashi, J. Antibiot., 29, 398 (1976).

7) S. Inoue, K. Okuda, H. Tanino, H. Kakoi and T. Goto, Chem. Lett., 1980, 297.

8) B. T. Ho, W. M. McIsaac, K. E. Walker and V. Estevez, J. Pharm. Sci., 57, 269 (1968).

9) Y.-I. Sung, K. Koike, T. Nikaido, T. Ohmoto and U. Sankawa, Chem. Pharm. Bull., 32, 1872 (1984).

10) H. Sakai, The Actinomycetologist, 36, 5 (1980). 